\title{
Psychosocial illness among the drug abusers undergoing detoxification in Dhaka, Bangladesh
}

\author{
Bushra Zaman ${ }^{1}$, SM Moslehuddin Ahmed ${ }^{2}$, Mir Mahmud Hossain ${ }^{3}$, Md. Mustafa Kamal
}

${ }^{1}$ Lecturer; ${ }^{2}$ Professor; Department of Community Medicine, Uttara Adhunik Medical College, Uttara, Dhaka. ${ }^{3}$ Consultant, Department of Anaesthesiology, Combined Military Hospital, Dhaka Cantonment, Dhaka. ${ }^{4}$ Assistant Professor, Department of Nutrition and Biochemistry, National Institute of Preventive and Social Medicine (NIPSOM), Mohakhali, Dhaka, Bangladesh.

\section{Abstract}

Abuse of drugs is a worldwide problem. Drug addiction is increasing tremendously in the South Asian countries especially in Bangladesh where such addiction is widespread among the younger age groups. It causes rapid erosion of educational, cultural, moral and family values. On the basis of defined criteria a total of 300 drug abusers who undergoing detoxification at the outpatient department of Central Drug Addiction Treatment Centre, Tejgaon, Dhaka were selected. The study was done for a period of one year from July 2013 to June 2014. Data were collected by face to face interview using pre-tested questionnaire. The analysis was done by computer using SPSS version 22.0. About $68 \%$ of the drug abusers had taken drugs for $2-5$ years and $38 \%$ had taken three drugs during their life time. The major influencing factor for taking drugs was for peer pressure. Among the drug abusers $77 \%$ had taken Ganja, 60\% Heroin as their first drug and 37\% Yaba as their last drug. The depression was measured by the Beck's Depression Inventory that showed $55 \%$ of the drug abusers had moderate depression, $23 \%$ borderline clinical depression, $15 \%$ mild mood disturbance, $4 \%$ severe depression, and 3\% had extreme depression. There were $\mathrm{s}$ ignificant associations between the duration of taking drugs $(p<0.001)$, the number of taking drugs $(p<0.006)$, and the age of first use of drugs $(p<0.019)$ with depression. Majority of the drug abusers had depression and a significant number of them were involved in antisocial activities as well as violence. Family and social participation, behavioral therapies and proper medical management are essential to control drug addiction.

Keywords: Psychological illness, Social illness, Drug addiction, Drug abusers, Detoxification.

\section{Introduction}

Now a days, substance abuse is recognized as an important public health problem in Bangladesh affecting not only the addicted persons but also the society as a whole. ${ }^{1}$ About 50 million people throughout the world is affected by it with devastating psychosocial effects. ${ }^{2}$ The term psychosocial refers to the psychological and social factors that influence mental health. ${ }^{3}$ In Bangladesh, the commonly abused substances include: Heroin, Phensidyl, Tidijesic, Pethidine, Cannabis, Ganja, Chorosh, Bhang, Yaba, Vayagra, Diazepam, Dexpotent, Alcohol, Cigarettes, Marijuana, Glue etc. ${ }^{4}$ Currently, Yaba has become popular and fashionable drug among the young and adolescents in Bangladesh. ${ }^{5}$ Bangladesh is situated in the central point between the 'golden triangle' (Myanmar, Thailand and Laos) and the 'golden crescent' (Pakistan, Afghanistan and Iran) in terms of geographical location and it is also surrounded by the major drug producing countries of Asia. ${ }^{3}$

Drug impacts directly influence the economic and social aspects of a country and physically to a human body. In Bangladesh, it has become a growing national concern. ${ }^{4}$ Among the treatment seeking drug abusers, depression is the most common substance abuse disorder. ${ }^{6,7,8}$ Drug abuse causes stress in a family, draining of family resources, shrinking from responsibilities, extramarital relations, distortion of interpersonal family relationships,

\section{Practice Points}

- Substance abuse is recognized as an important public health problem in Bangladesh.

- In the present study, peer pressure was found to be the major influencing factor for taking drugs and a significant number of drug abusers suffered depression.

- Majority of the drug abusers had taken drugs for two to five years and more than one third of the drug abusers abused three or more drugs during their life time.

- The duration of taking drugs, the number of taking drugs and the age of first use of drugs were significantly associated with depression.

- Family and social participation, behavioral therapies and proper medical management are essential to control drug addiction.

violence, sickness and death. ${ }^{9}$ The societal cost of drug abuse is enormous and multifaceted. Drug addiction also has association with crime which includes drug peddling, petty crimes, and road accidents committed under the influence of drug. Drug addiction has an impact on work. Most of the addicts are unable to

Correspondence: Dr. Bushra Zaman, Lecturer, Department of Community Medicine, Uttara Adhunik Medical College, Uttara, Dhaka, Bangladesh. Email: bushrazaman1972@yahoo.com. 
work, and students cannot attend to their studies. ${ }^{10}$ Among drug abusers, intravenous drug use has the potential to turn a slow HIV epidemic into an explosive and devastating one. ${ }^{3}$ Drug addiction leads to disintegration of family life. Social isolation and alienation are very common. The drug abusers swallow the lion share of family income for buying drugs. ${ }^{11}$

The aim of study was to investigate the psychosocial illness among the drug abusers undergoing detoxification in an addiction treatment centre in Dhaka, Bangladesh.

\section{Materials and Methods}

This cross-sectional study was conducted during July 2013 to June 2014 among 300 drug abusers attending at the outpatient department of the Central Drug Addiction Treatment Centre, Tejgaon, Dhaka, Bangladesh. It is the only government hospital located in Dhaka city where detoxification facilities are available for male substance abusers. Respondents were selected who fulfilled the inclusion criteria like age limit between 18-40 years, had a history of drug abuse for more than 2 years, and had started drug abuse detoxification treatment within the last six weeks. Persons suffering from primary mental disorders, physical disabilities, acute or chronic illness within the study period and using prescribed medication were not included in the study. Data had been collected from the respondents by interviewers using a questionnaire. The questionnaire was pretested among the drug abusers and subsequently finalized after necessary modifications. The pretested participants were excluded from the study. Before data collection a written consent was taken from each of the drug abusers or from their legal guardian.

The collected data were processed, compiled and analyzed by computer using SPSS (Statistical Package for Social Science) version 22.0. The results were then furnished in descriptive statistics as frequency, percentage, mean and standard deviation in tables. Nonparametric Chi square tests were done to see any significant association. For all statistical analysis, $p$ values less than 0.05 were considered significant. The Beck's Depression Inventory ${ }^{12}$ was used to assess the depression among the drug abusers. It is one of the most widely used instruments for measuring the severity of depression which has twenty-one multiple-choice questions. So the highest possible total for the whole test was sixty-three and the lowest possible score for the test was zero. It was composed of items relating to symptoms of depression such as hopelessness and irritability, cognitions such as guilt or feelings of being punished, as well as physical symptoms such as fatigue, weight loss, insomnia, loss of appetite and lack of interest in sex.

\section{Results}

The drug history of the abusers were summarized in Table 1. Most of the drug abusers (68\%) had taken drugs for 2-5 years and the mean duration of drug abuse was $5.16 \pm 3.45$ years. About $38 \%$ of the drug abusers had taken three drugs during their life time. Nearly half of the drug abusers (58\%) started their first use of drug

Table 1: Distribution of the drug abusers by drug history (n- 300)

\begin{tabular}{|l|c|c|}
\hline Parameters & Frequency (\%) & Mean \pm SD \\
\hline Duration of taking drugs (years) & $204(68 \%)$ & $5.16 \pm 3.45$ \\
$2-5$ & $72(24 \%)$ & \\
$6-10$ & $15(5 \%)$ & \\
$11-15$ & $9(3 \%)$ & \\
$16-20$ & $60(20 \%)$ & $3.37 \pm 0.98$ \\
\hline Number of drugs taken & $114(38 \%)$ & \\
Two drugs & $87(29 \%)$ & \\
Three drugs & $33(11 \%)$ & \\
Four drugs & $6(2 \%)$ & \\
Five drugs & $174(58 \%)$ & \\
Six drugs & $84(28 \%)$ & \\
\hline Age of first drug use (years) & $36(12 \%)$ & \\
$<20$ & $6(2 \%)$ & \\
$21-25$ & $159(53 \%)$ & \\
$26-30$ & $114(38 \%)$ & \\
$31-35$ & $66(22 \%)$ & \\
\hline Influencing factors & $57(19 \%)$ & \\
Peer pressure & $42(14 \%)$ & \\
Getting pleasure & $24(8 \%)$ & \\
Curiosity & $12(4 \%)$ & \\
Depression & $6(2 \%)$ & \\
Friend's incitement & $3(1 \%)$ & \\
Failure in love & & \\
Loneliness & & \\
Unemployment & & \\
Family conflict & & \\
\hline
\end{tabular}


at the age $<20$ years and the mean age of first drug use by the drug abusers was $21.37 \pm 3.66$ years. The major reasons of taking drugs were peer pressure $(53 \%)$, getting pleasure (38\%), curiosity (22\%), depression (19\%), friend's incitement (14\%) and failure in love (8\%).

Table 2 showed the current use of the most common type of drugs by the drug abusers. The most common drugs was Ganja (77\%), followed by Heroin (69.3\%), Yaba (62\%), Phensidyl (52\%), and injection (33\%). About $60 \%$ of the drug abusers had taken Heroin, 20\% Ganja, and 19\% Phensidyl as their first drug. Thirty seven percent of the drug abusers had taken Yaba, 32\% injection and $21 \%$ Ganja as their last drugs.

Table 3 showed the psychological problems of the drug abusers; majority of the abusers were suffering from depression (92\%), insomnia (91\%), and reduced appetite $(69 \%)$. Table 4 showed the grading of depression of the drug abusers according to the Beck's Depression Inventory. It was found that majority of the respondents $55 \%$ had moderate depression followed by borderline clinical depression $23 \%$, and mild mood disturbance $15 \%$.

Table 2: Drug abusing profile of the drug abusers (n-300)

\begin{tabular}{|l|c|c|c|}
\hline Drugs & Present drug abuse & First drug abused & Last drug abused \\
\hline Heroin & $208(69.3 \%)$ & $180(60 \%)$ & $0(0 \%)$ \\
\hline Phensidyl & $156(52 \%)$ & $57(19 \%)$ & $6(2 \%)$ \\
\hline Ganja & $231(77 \%)$ & $60(20 \%)$ & $63(21 \%)$ \\
\hline Sedatives & $30(10 \%)$ & $3(1 \%)$ & $3(1 \%)$ \\
\hline Yaba & $186(62 \%)$ & $0(0 \%)$ & $311(37 \%)$ \\
\hline Danti & $30(10 \%)$ & $0(0 \%)$ & $3(1 \%)$ \\
\hline Shisha/Hukka & $24(8 \%)$ & $0(0 \%)$ & $15(5 \%)$ \\
\hline Cough syrup & $51(17 \%)$ & $0(0 \%)$ & $96(32 \%)$ \\
\hline $\begin{array}{l}\text { Injection (Buprenorphine, } \\
\text { Pethedine, Morphine etc) }\end{array}$ & $99(33 \%)$ & $0(0 \%)$ & \\
\hline
\end{tabular}

Table 3: Distribution of the drug abusers by psychological problems (n- 300)

\begin{tabular}{|l|c|}
\hline Parameters & Frequency (\%) \\
\hline Depression & $276(92 \%)$ \\
Yes & $24(8 \%)$ \\
No & \\
\hline Anxiety & $15(5 \%)$ \\
Yes & $285(95 \%)$ \\
No & \\
\hline Aggressive outburst & $42(14 \%)$ \\
Yes & $258(86 \%)$ \\
No & $33(11 \%)$ \\
\hline Self-harm & $267(89 \%)$ \\
Yes & \\
No & $273(91 \%)$ \\
\hline Insomnia & $27(9 \%)$ \\
Yes & \\
No & $207(69 \%)$ \\
\hline Reduced appetite & $93(31 \%)$ \\
Yes & \\
No & $3(1 \%)$ \\
\hline Others & $297(99 \%)$ \\
Yes & \\
No & \\
\hline
\end{tabular}

Table 4: Distribution of drug abusers by grading of depression (Beck's Depression Inventory) (n-300)

\begin{tabular}{|l|c|}
\hline Parameters & Frequency (\%) \\
\hline Mild mood disturbance (11-16) & $45(15 \%)$ \\
Borderline clinical depression (17-20) & $69(23 \%)$ \\
Moderate depression $(21-30)$ & $165(55 \%)$ \\
Severe depression $(31-40)$ & $12(4 \%)$ \\
Extreme depression $(>40)$ & $9(3 \%)$ \\
\hline
\end{tabular}

Table 5: Social effects of drug abuse (n- 300)

\begin{tabular}{|l|c|}
\hline Parameters & $\begin{array}{c}\text { Frequency } \\
(\mathbf{\%})\end{array}$ \\
\hline Antisocial activities & \\
Illegal gambling & $87(29 \%)$ \\
Snatching & $24(8 \%)$ \\
Stealing & $3(1 \%)$ \\
Violence & $186(62 \%)$ \\
\hline Effects on education & \\
Irregular academic attendance & $15(5 \%)$ \\
Poorer result than before & $18(6 \%)$ \\
Lack of interest in learning & $51(17 \%)$ \\
Drop out from studies & $54(18 \%)$ \\
Expulsion from school & $6(2 \%)$ \\
Not applicable & $156(52 \%)$ \\
\hline Effects on job & \\
Losing job & $30(10 \%)$ \\
Clash with colleagues & $3(1 \%)$ \\
Inferiority complex & $114(38 \%)$ \\
Unskilled performance & $42(14 \%)$ \\
Absenteeism & $27(9 \%)$ \\
Accidents during the job & $78(26 \%)$ \\
Frequent change of job & $3(1 \%)$ \\
Not applicable & $3(1 \%)$ \\
\hline Problems with law enforcing & \\
agencies & $12(4 \%)$ \\
Arrested for conducting crime & $24(8 \%)$ \\
Drug influenced behavior & $126(42 \%)$ \\
Arrested for possessing/selling & \\
drugs & $120(40 \%)$ \\
Jail sentence and fine & \\
Harassment by police & \\
\hline
\end{tabular}


It was also revealed that drug abusers were involved in various antisocial activities i.e. violence $62 \%$, illegal gambling 29\%, and snatching $8 \%$ (Table 5). About $18 \%$ of the drug abusers were dropped out from studies, $38 \%$ suffered from inferiority complex, and $42 \%$ were arrested for possessing/selling illegal drugs. Table 6 showed that the duration of taking drugs $(p<0.001)$, the number of taking drugs $(p<0.006)$ and the age of first use of drug were significantly $(p<0.019)$ associated with depression. The first drug taken by the drug abusers was also associated $(p<0.003)$ with depression.

\section{Discussion}

In the present study, majority of the drug abusers (68\%) had taken drugs for 2-5 years and the mean duration of drug abuse was $5.16 \pm 3.45$ years. About three-quarters of the respondents had taken 3-5 drugs during their life time. Another study conducted by Hossain et al. ${ }^{13}$ found that multiple drug use for a long period (more than 5 years) was highly prevalent among the drug abusers in Bangladesh. Nearly half of the drug abusers $(58 \%)$ started their first use of drug at the age $<20$ years and the mean age of first drug use by the drug abusers was 21.37 years. A study in India showed that most of the users had initiated substance abuse during 15-18 years of age. ${ }^{14} \mathrm{We}$ also found that the peer pressure, pleasure and curiosity were the major influencing factor of abusing drug. This result is consistent with another study conducted by Riya et $a l .{ }^{15}$ found that peer pressure was a major contributing factor $(55.5 \%)$ for drug initiation. Similar findings were also reported by Gopiram, ${ }^{14}$ where peer influence, curiosity and sense of growing being were the major reasons of taking drugs among adolescents and young adults in India. 'Feel good' and 'socialization' were the main reasons for maintenance. ${ }^{14}$ Another study done by Khatun ${ }^{1}$ in Bangladesh showed that most of the respondents learnt drug use from peer group. In addition, a significant number of respondents $(59.76 \%)$ reported that they took drug because of curiosity or making fun.

The most commonly used drugs were Ganja (77\%), Heroin (69.3\%), Yaba (62\%), and Phensidyl (52\%). About $60 \%$ of the drug abusers used Heroin as their first drug. Bangladesh is not heroin producing country but it is in the midst of the international drug trafficking zones. In addition, drug addicts choose heroin may be due to its highest euphoric characteristics compared to other abused substances. ${ }^{13}$ Thirty seven percent of the drug abusers had taken Yaba and 32\% had taken injection as their last drug. Due to change in the trend of drug use, now a days a significant number of drug abusers use Yaba. A study conducted by Khatun $^{1}$ in Bangladesh found that almost half of the drug users were taking Yaba. However, one of the limitations of the study was small sample size. ${ }^{1}$ Regarding inhalation as the primary drug abuse was Heroin in our study and the findings is consistent with the findings of the study done by Sau et al. ${ }^{2}$ in India.

The present study found that most of the drug abusers were suffering from a number of psychological problems i.e. depression (92\%), insomnia (91\%), reduced appetite $(69 \%)$ etc. These findings are similar to a study conducted by Hossain et al. ${ }^{16}$ where he found that $7.3 \%-92.5 \%$ of the substance abusers had been suffering from mental illnesses. Insomnias, decreased intake of food and taste preference, irritable $\mathrm{mood} /$ affects, loss of interest in sex and non-specific anxieties were highly prevalent among them. ${ }^{16}$ Depression was also found to the most common disorder in a number of studies in Nigeria ${ }^{17}$ and USA. ${ }^{18-20}$ Most of the respondents in our study were suffering from moderate depression $(55 \%)$ and borderline clinical depression (23\%), and were engaged in various antisocial activities i.e. violence $(62 \%)$, illegal gambling $(29 \%)$ etc. In a study conducted by Hossain et $a l .{ }^{13}$ in Bangladesh found that violence, illegal

Table 6: Association between drug history of the abusers and depression (n-300)

\begin{tabular}{|c|c|c|c|c|}
\hline \multirow[t]{2}{*}{ Parameters } & \multicolumn{2}{|c|}{ Depression } & \multirow[t]{2}{*}{ Chi-square test } & \multirow[t]{2}{*}{$p$-value } \\
\hline & $\begin{array}{c}\text { Yes } \\
\text { No. }(\%) \\
\end{array}$ & $\begin{array}{c}\text { No } \\
\text { No. }(\%) \\
\end{array}$ & & \\
\hline $\begin{array}{l}\text { Duration of taking drugs (years) } \\
2-5 \\
6-10 \\
11-15 \\
16-20\end{array}$ & $\begin{array}{r}192(94.1 \%) \\
66(91.7 \%) \\
12(80.0 \%) \\
6(66.7 \%)\end{array}$ & $\begin{array}{r}12(5.9 \%) \\
6(8.3 \%) \\
3(20.0 \%) \\
3(33.3 \%)\end{array}$ & 68.569 & 0.001 \\
\hline $\begin{array}{l}\text { Number of drugs taken } \\
\text { Two drugs } \\
\text { Three drugs } \\
\text { Four drugs } \\
\text { Five drugs } \\
\text { Six drugs } \\
\end{array}$ & $\begin{array}{r}48(80.0 \%) \\
108(94.7 \%) \\
81(93.1 \%) \\
33(100.0 \%) \\
6(100.0 \%) \\
\end{array}$ & $\begin{array}{r}12(20.0 \%) \\
6(5.3 \%) \\
6(6.9 \%) \\
0(0.0 \%) \\
0(0.0 \%) \\
\end{array}$ & 16.435 & 0.006 \\
\hline $\begin{array}{l}\text { Age of first use of drug (years) } \\
\quad<20 \\
\quad 21-25 \\
26-30 \\
31-35\end{array}$ & $\begin{array}{r}162(93.1 \%) \\
72(85.7 \%) \\
36(100.0 \%) \\
6(100.0 \%)\end{array}$ & $\begin{array}{r}12(6.9 \%) \\
12(14.3 \%) \\
0(0.0 \%) \\
0(0.0 \%)\end{array}$ & 43.207 & 0.019 \\
\hline
\end{tabular}


gambling, snatching, mugging and stealing were extremely prevalent among the illicit substance abusers.

In our study, we found that about half of the drug abusers had some sort of academic or school related problems and almost everyone had problems with job and conflicts with law enforcing agencies. These findings are also comparable to a survey conducted by Sharma ${ }^{10}$ in India, where he reported that two-fifths of addicts came in conflict with the law, almost threefourths of addicts were unable to work, and students could not attend to their studies. Though the study findings are usual phenomenon in Bangladesh but no such study was found regarding these problems to compare.

Drug addicts are burdens for a family and society. It is a great challenge for all nations of the world to prevent drug addiction. ${ }^{11}$ As drug abuse is a chronic illness, the aim of its holistic management is to make the clients free from drugs within a sustainable period. It has been observed that repeated relapse is common among drug abusers. $^{2}$ Before the problems get serious an early identification of the magnitude and the factors related to substance abuse can improve scopes for planning and preventive approaches for this vulnerable group otherwise interventions would become much more difficult and complex. ${ }^{21,22}$

One of the limitations of the study is that the findings can't be generalized as it was conducted in the Central Drug Addiction Treatment Centre, Dhaka where only male drug abusers are treated.

\section{Conclusion}

Drug addiction is an important public health problem in Bangladesh and the prevalence is increasing with time. The present study findings revealed that substance abuse increases the risk of associated psychosocial disorders and the most common disorder was depression. Adolescents and young adults use substance for various socio-economic reasons despite knowing the harmful effects of substance. The major influencing factor of taking drugs among the drug abusers was peer pressure and the first drug of experience was heroin. Majority of the drug abusers were also involved in antisocial activities. Family support, controlling easy availability of drugs, treatment of withdrawal symptoms and restoration of social, moral and religious values could be helpful in combating drug addiction.

\section{References}

1. Khatun MT, Anwar MS. Public concern towards drug addiction. Bangladesh Res Publ J 2013;9(1):22-8.

2. Sau M, Mukherjee A, Manna N, Sanyal S. Socio-demographic and substance use correlates of repeated relapse among patients presenting for relapse treatment at an addiction treatment center in Kolkata, India. Afr Health
Sci 2013;13(3):791-9.

3. Rahman M, Zaman MS, Sakamoto J, Fukui T. How much do drug abusers pay for drugs in Bangladesh? J Health Popul Nutr 2004;22 (1):98-9.

4. Shemul H. The impact of drugs on young generation of Bangladesh. http:// www.modernghana.com/news/211261/1/theimpacts-of-drugs-on-young-generation-ofbangla.html (accessed March 2014)

5. WebMD. Drug abuse, addiction, and the brain. http://www.webmd.com/mental-health/ addiction/drug-abuse-addiction (accessed April 2014)

6. Stulz N, Michael E, Gallop R, Crits P. Psychosocial treatment for cocaine dependence: The role of depressive symptoms. J Drug Alcohol Depend 2011;114(1):41-8.

7. Onyeka IN, Beynon CM, Uosukainen $\mathrm{H}$, Korhonen MJ. Coexisting social conditions and health problems among clients seeking treatment for illicit drug use in Finland: The HUUTI study. Bio Med Central Public Health 2013; $13: 380$.

8. Nasirzadeh M, Eslami AA, Sharifirad G, Hasanzadeh A. The mental health and substance abuse among youths aged 18 to 29: A comparative study. $J$ Educ Health Promot 2013;2:34.

9. Islam RN, Tabassum NE, Shafiuzzaman AKM, Umar BU, Khanam M. Methamphetamine (YABA) abuse: A case study in young male. Faridpur Med Coll J 2012;7(2):102-4.

10. Sharma U. Social consequences of drug abuse in South-Asia. http://www.drugabuse.gov/ international/abstracts/social-consequencesdrug-abuse-in-south-asia (accessed May 2014)

11. Shazzad MN, Abdal SJ, Majumder MSM, Sohel JUA, Ali SMM, Ahmed S. Drug addiction in Bangladesh and its effect. Med today 2013;25(2):84-9.

12. Beck AT, Ward CH, Mendelson M. An inventory for measuring depression. Arch Gen Psychiatry 1961;4:561-71.

13. Hossain KJ, Karim MR, Masud A, Karim MN, Kamal MM. Sex-habit and sexually transmitted infection (STIs) among the drug abusers undergoing detoxification. J Med 2013;14:5-10.

14. Gopiram P, Kishore MT. Psychosocial attributes of substance abuse among adolescents and young adults: A comparative study of users and non-users. Indian J Psychol Med 2014;36(1):58-61.

15. Riya S, Rahman M, Sadeque MZ, Kabir A, Umar BU. Pattern of drug abuse among patients in some selected addiction rehabilita- 
tion centers in Dhaka city. Faridpur Med Coll J 2013;8(2):63-6.

16. Hossain KJ, Nandi AK, Karim MR, Haque MM, Kamal MM. Pattern of mental illness on substance abusers. Mymensingh Med J 2012;21 (2):251-8.

17. Igwe WC, Ojinnaka NC. Mental health of adolescents who abuse psychoactive substances in Enugu, Nigeria: A cross-sectional study. Ital J Pediatr 2010;36:53.

18. Booth BM, Walton MA, Barry KL, Rebecca M, Cunningham RM, Chermack ST, Blow FC. Substance use, depression and mental health functioning in patients seeking acute medical care in an Inner-City ED. J Behav Health Serv Res 2011;38(3):358-72.

19. McKowen JW, Tompson MC, Brown TA, Psy D, Asarnow JR. Longitudinal associations between depression and problematic substance use in the youth partners in care study. J Clin Child Adolesc Psychol 2013;42(5):669-80.

20. Greenfield BL, Venner KL, Kelly JF, Slaymaker V, Bryan AD. The impact of depression on abstinence self-efficacy and substance use outcomes among emerging adults in residential treatment. Psychol Addict Behav 2012;26(2):246-54.

21. Tsering D, Pal R, Dasgupta A. Licit and illicit substance use by adolescent students in Eastern India: Prevalence and associated risk factors. $J$ Neurosci Rural Pract 2010;1(2):75-81.

22. Saban A, Flisher AJ, Grimsrud A, Morojele N, London L, Williams DR, Stein DJ. The association between substance use and common mental disorders in young adults: Results from the South African Stress and Health (SASH) Survey. Pan Afr Med J 2014;17( Supp 1):11. 